\title{
The Life of a Painting as Traced by Technical Analysis: Original Materials and Posthumous Alterations in Édouard Manet's Woman in Striped Dress
}

\author{
Federica Pozzi ${ }^{1, *,+}{ }^{\circ}$, Silvia A. Centeno ${ }^{1}$, Federico Carò ${ }^{1}$, Gillian McMillan ${ }^{2}$, Lena Stringari ${ }^{2}$ and Vivien Greene ${ }^{3}$ \\ 1 Department of Scientific Research, The Metropolitan Museum of Art, 1000 Fifth Avenue, New York, NY 10028, \\ USA; silvia.centeno@metmuseum.org (S.A.C.); federico.caro@metmuseum.org (F.C.) \\ 2 Conservation Department, Solomon R. Guggenheim Museum, 1071 Fifth Avenue, New York, NY 10128, USA; \\ gmcmillan@guggenheim.org (G.M.); lstringari@guggenheim.org (L.S.) \\ 3 Curatorial Department, Solomon R. Guggenheim Museum, 1071 Fifth Avenue, New York, NY 10128, USA; \\ vgreene@guggenheim.org \\ * Correspondence: federica.pozzi@centrorestaurovenaria.it \\ + Current address: Center for Conservation and Restoration of Cultural Heritage "La Venaria Reale", \\ Via XX Settembre 18, 10078 Venaria Reale, TO, Italy.
}

check for

updates

Citation: Pozzi, F.; Centeno, S.A.; Carò, F.; McMillan, G.; Stringari, L.; Greene, V. The Life of a Painting as Traced by Technical Analysis: Original Materials and Posthumous Alterations in Édouard Manet's Woman in Striped Dress. Coatings 2021, 11, 1334. https://doi.org/10.3390/ coatings11111334

Academic Editor: Maurizio Licchelli

Received: 23 September 2021

Accepted: 26 October 2021

Published: 30 October 2021

Publisher's Note: MDPI stays neutral with regard to jurisdictional claims in published maps and institutional affiliations.

Copyright: (c) 2021 by the authors. Licensee MDPI, Basel, Switzerland. This article is an open access article distributed under the terms and conditions of the Creative Commons Attribution (CC BY) license (https:/ / creativecommons.org/licenses/by/ $4.0 /)$.

\begin{abstract}
Among the holdings of the Solomon R. Guggenheim Foundation, New York, is a large-scale portrait by Édouard Manet that remained apparently unfinished upon the artist's death, in April 1883. This work, now known as Woman in Striped Dress, belongs to Manet's late artistic production and dates from around 1877 to 1880 . A collaborative endeavor entailing archival research and scientific analysis revealed that the composition had suffered dramatic alterations prior to its arrival at the museum in 1965 as an extended loan, likely carried out to "finish" the picture in order that it would be marketable and to increase its sale value. Among the main changes explored in this technical study are the reductions in the canvas size and subsequent varnishing campaigns. Furthermore, along with a detailed characterization of the original materials present in the ground and paint layers, this research contributed to the identification of posthumous retouchings, possibly executed concurrently with trimming the canvas along both sides and at the top edge. The investigation was instrumental in devising an appropriate treatment to remove the discolored varnish and select areas of retouching, which obscured significant details of the composition and Manet's delicate brushwork.
\end{abstract}

Keywords: Manet; painting; portrait; woman; 19th century; pigments; extenders; varnish; original materials; later alterations

\section{Introduction}

When Édouard Manet died in April 1883, more than one hundred paintings in various stages of completion were left in his studio in Paris. Among these was a large-scale picture of a woman, possibly unfinished, now known as Woman in Striped Dress (Figure 1) [1,2]. Belonging to the artist's late oeuvre and dating from around 1877 to 1880, this painting is housed in the Thannhauser collection at the Solomon R. Guggenheim Museum, New York. It depicts an unknown model, possibly a courtesan dressed up for the occasion, standing before an unidentified background, likely staged inside the artist's studio. This picture resembles many of Manet's late paintings, which often appear to be rapidly executed and characterized by broad, lively brushwork applied in a direct manner. Entire passages of his compositions are typically dominated by just a few paint strokes, in the pursuit of an instantaneous translation of visual experience onto the two-dimensional canvas. As the artist told his lifelong friend Antonin Proust: "There's just one real thing. To get down what one sees at the first shot. When it's there, it's there. When it's not there, one starts over. Everything else is nonsense" [3]. However, the artist is known to have struggled between perfectionism and spontaneity, laboring over certain passages and scraping away areas he did not deem 
successful in order to rework them [4,5]. The extent to which Manet considered this large portrait complete is unknown; however, the predominant aesthetic of the time expected more finished paintings, which might explain the posthumous alterations realized to make this work more marketable.
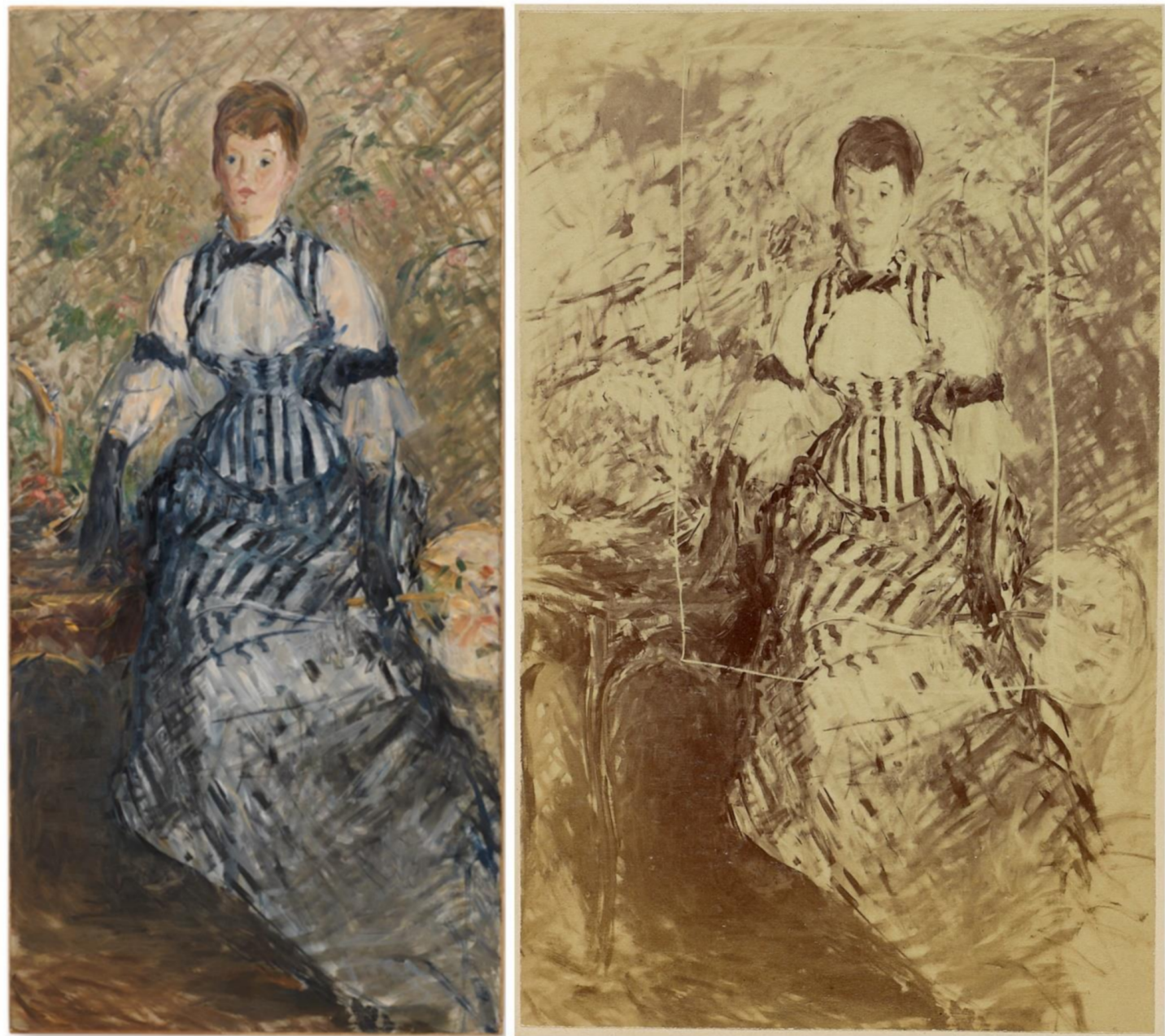

Figure 1. (Left), Édouard Manet, Woman in Striped Dress, ca. 1877-80. Oil on canvas, $175.5 \times 84.3 \mathrm{~cm}$. Solomon R. Guggenheim Museum, New York, Thannhauser Collection, Gift, Justin K. Thannhauser, 1978, 78.2514.24 @ Solomon R. Guggenheim Foundation, New York. Photograph taken in 2015, before conservation treatment. (Right), the painting as photographed by Fernand Lochard in the artist's studio (photo no. 118), Paris, ca. $1883-84,10.5 \times 6.5 \mathrm{~cm}$.

A comparison of Woman in Striped Dress with a historical image that photographer Fernand Lochard took around 1884 after Manet's death (Figure 1) revealed that the painting suffered a series of dramatic alterations prior to its arrival at the Guggenheim in 1965 as an extended loan, after it was promised as a gift in 1963. Captured at the request of the artist's stepson, Léon Leenhoff, to record the contents of the artist's studio, the Lochard photograph shows, for instance, a rectangular outline drawn around much of the woman's figure. This rough outline suggests that someone-potentially Manet, or else his heirs, friends, or dealers-may have considered reducing the size of the work on all four sides. Accordingly, compared to the original composition as shown in these photographs, the canvas appears to have been cut down to a more vertical format, perhaps in an effort to remove the sketchiest areas of brushwork or to further highlight the model and her finery. Another hand (or hands) also embellished and retouched the work, and numerous additions were made to fill in some incomplete areas of the composition. These changes were likely executed concurrently with the cutting down, as some of the brushwork ends abruptly near the "new" edge of the painting. At a later date, the work lost a few additional 
centimeters, possibly in conjunction with the attachment of its present lining on the reverse of the canvas, resulting in its current dimensions.

The application of multiple varnish layers, the uppermost of which was immediately evident upon observation of the surface, further compromised the original appearance of Woman in Striped Dress. Besides visually flattening the composition, these coatings, which had discolored to a dark greenish-yellow tone over time, partially disguised the retouches. The topmost varnish layer, of a particularly thick and glossy appearance, was likely applied after the Galerie Thannhauser, owned by Justin K. Thannhauser, purchased the painting in 1928. Performed around the same time as the lining treatment, this latest varnishing campaign was perhaps meant to further conceal the discrepancies of the various revisions made to the work. Together with the size reductions and painted embellishments, these coating applications may represent additional attempts to make the picture seem more acceptably finished and therefore desirable to a larger, traditional collector base.

In this context, a comprehensive technical study of Manet's Woman in Striped Dress sought to shed light on the original materials the artist used and on the later alterations suffered by the painting during its lifetime, as it passed from one owner to the next. For this purpose, a combination of non-invasive and micro-invasive techniques, as well as portable and benchtop instrumentation, was employed both in the Guggenheim's conservation laboratory and in the Department of Scientific Research (DSR) of The Metropolitan Museum of Art (The Met). In addition to augmenting the current scholarship regarding a pivotal figure of the late 19th century who straddled multiple "isms" while remaining singular in his pictorial production, the findings presented here contributed to the design of a suitable cleaning treatment for the painting, aiming to remove the yellowed superficial varnish and some of the later retouchings. The overall appearance of Woman in Striped Dress is now comparable to other Manet portraits of a similar date, with its masterful brushwork and sketchy matte finish. While the work can never be returned entirely to its original scale and condition, it now better captures the spirit of modernity not fully appreciated—certainly in more conservative camps-at the time of its creation.

\section{Materials and Methods}

The present study of Manet's Woman in Striped Dress relied on in situ, non-invasive measurements with portable equipment, followed by the removal and investigation of microscopic samples through benchtop instrumentation. Initial examination of the painting involved an imaging campaign using normal light and infrared (IR) illumination, as well as analysis with X-radiography and handheld X-ray fluorescence (XRF) spectroscopy. After these preliminary investigations, all carried out in the Guggenheim's conservation studio, the work was transferred to The Met for macro-XRF (MA-XRF) analysis. With the invaluable help and guidance of the Guggenheim's conservators, sixteen microscopic scrapings and samples for cross sections were then removed from the woman's dress and from areas of possible later retouching for investigation with optical microscopy and analysis by transmission Fourier-transform infrared (FTIR) and Raman spectroscopies, scanning electron microscopy with energy-dispersive X-ray spectroscopy (SEM/EDS), and electron backscatter diffraction (EBSD). These analyses on the paint stratigraphy were conducted to provide a conclusive identification of the variety of pigments and extenders present in the ground and paint layers. Some of the sample scrapings were also investigated with pyrolysis—gas chromatography/mass spectrometry (Py-GC/MS) for a detailed characterization of the uppermost varnish. Figure 2 reports an indication of the locations where samples were removed for this study, to be referred to from here on whenever scrapings and cross sections are mentioned. Experimental conditions for the analytical techniques employed are reported below.

\subsection{IR Reflectography and Transmittography}

Imaging was conducted using an Osiris shortwave IR (SWIR) imager (OPUS Instruments, Norwich, UK), equipped with an InGaAs detector with sensitivity in the 
900-1700 nm range. An $850 \mathrm{~nm}$ long-pass IR filter was used with a Rodagon $150 \mathrm{~mm}$ f/5.6 lens, optimized for the IR region. The Osiris SWIR imager has a linear 512-pixel sensor within a precision-geared mechanism that assembles a final $4096 \times 4096$-pixel image file. Images were post-processed and optimized with Adobe Photoshop software.

\subsection{X-Radiography}

Imaging was carried out with a Picker Hotshot AXR X-ray system (Associated XRay Corporation, New Haven, CT, USA). Images were captured at $45 \mathrm{kV}, 3 \mathrm{~mA}$, and $45 \mathrm{~s}$, and were digitized and stitched at the Northeast Document Conservation Center (NEDCC), using a GE model FS50B X-ray scanner. The scanner utilized GE Rhythm Acquire version 4.0 and Rhythm Review version 4.0 to process the files. Stitching and other post-processing work was performed with a combination of PTGui and Adobe Photoshop software.

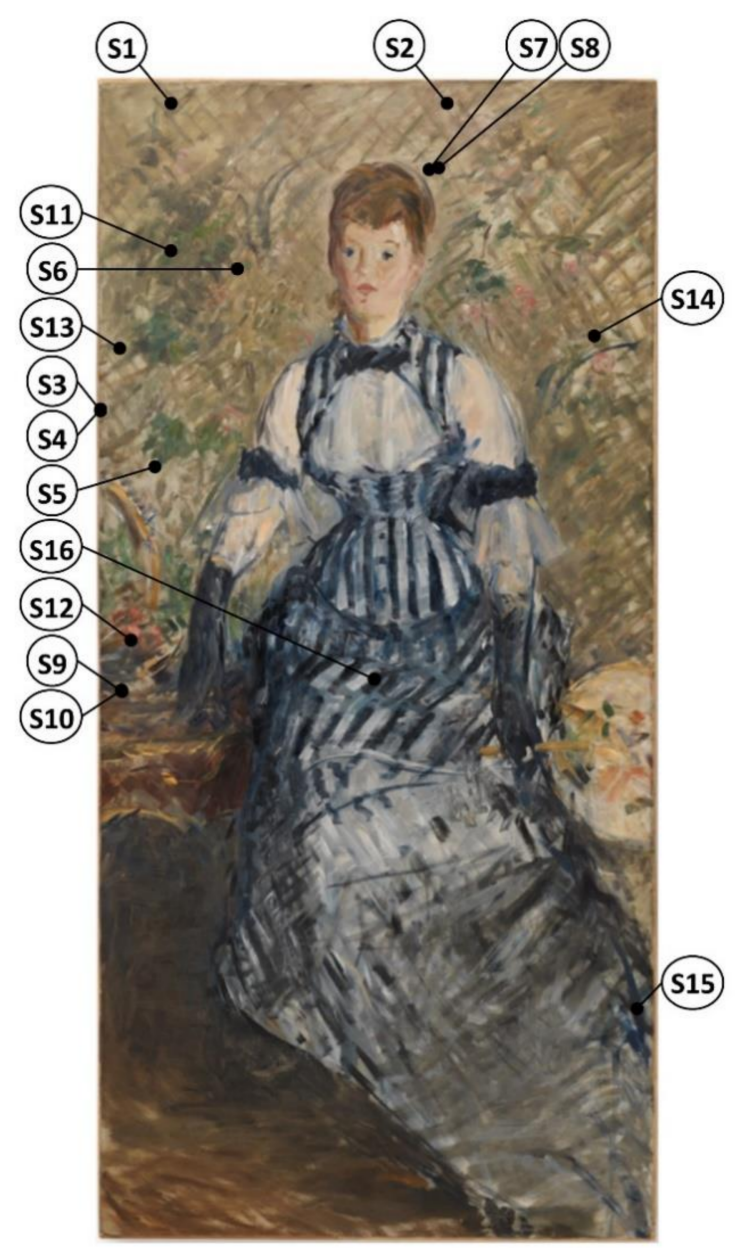

Figure 2. Sampling sites for Manet's Woman in Striped Dress.

\subsection{Point XRF}

Analysis was performed using a handheld Bruker Tracer III- $\mathrm{V}^{\mathrm{TM}}$ energy dispersive XRF analyzer (Bruker Corporation, Berlin, Germany), with Peltier-cooled advanced highresolution silver-free Si-PIN detector with a $0.2 \mu \mathrm{m}$ beryllium (Be) window and average resolution of approximately $142 \mathrm{eV}$ for the full width at half maximum of the manganese $(\mathrm{Mn}) \mathrm{K} \alpha$ line. The system is equipped with changeable filters, and a rhodium (Rh) transmission target with maximum voltage of $45 \mathrm{kV}$ and tunable beam current of 2-25 $\mu \mathrm{A}$. The size of the spot analyzed is approximately $3 \times 4 \mathrm{~mm}$. Experimental parameters were $40 \mathrm{kV}$, $12.5 \mu \mathrm{A}$, and $120 \mathrm{~s}$ acquisition time, and a titanium (Ti)-aluminum (Al) filter was used. 
Measurements were acquired by positioning the instrument at $\mathrm{a} \approx 1 \mathrm{~mm}$ distance from the artwork's surface.

\section{4. $M A-X R F$}

Mapping was carried out using a Bruker M6 Jetstream ${ }^{\circledR}$ instrument (Bruker Corporation, Berlin, Germany) equipped with a $30 \mathrm{~mm}^{2}$ XFlash silicon drift detector (SDD) and an air-cooled micro-focus Rh target X-ray tube operated at $50 \mathrm{kV}$ and $0.5 \mathrm{~mA}$. Five areas of the painting were mapped with a $700 \mu \mathrm{m}$ spot size, an $800 \mu \mathrm{m}$ step, and a dwell time of $90 \mathrm{~ms} /$ pixel. Spectra were processed using the Bruker M6 Jetstream software.

\subsection{FTIR}

Analysis was conducted in transmission mode with a Hyperion 3000 FTIR spectrometer (Bruker Corporation, Berlin, Germany) equipped with a mercury cadmium telluride (MCT) detector. Each sample was crushed in a Spectra Tech diamond anvil cell and all the materials contained in it were analyzed as a bulk through a $15 \times$ objective. Spectra were collected in the $4000-600 \mathrm{~cm}^{-1}$ range, at a resolution of $4 \mathrm{~cm}^{-1}$, as the sum of 128 or 256 scans, depending on the spectral response of the samples examined.

\subsection{Raman}

Spectra were acquired with a Bruker Senterra Raman spectrometer (Bruker Corporation, Berlin, Germany) equipped with an Olympus $50 \times$ long working distance objective and a charge-coupled device (CCD) detector. A Spectra Physics Cyan solid-state laser, a Melles Griot He-Ne laser, and a continuous wave diode laser, emitting light at 488, 633, and $785 \mathrm{~nm}$ respectively, were used as the excitation sources, and two holographic gratings (1800 and 1200 rulings $/ \mathrm{mm}$ ) provided a spectral resolution of $3-5 \mathrm{~cm}^{-1}$. The output laser power was kept below $25 \mathrm{~mW}$, while the number of scans and integration time were adjusted to prevent damage from overheating and according to the spectral response of the samples examined.

\subsection{SEM/EDS}

Analysis of cross sections was performed with a FE-SEM Zeiss Eigma HD system (Zeiss, Oberkochen, Germany) equipped with an Oxford Instrument X-MaxN 80 SDD (Oxford, Tubney Woods, Abingdon, Oxon, UK). Back-scattered electron (BSE) imaging, as well as EDS elemental spot analysis and mapping, were performed in high vacuum with an accelerating voltage of $20 \mathrm{kV}$, on $12 \mathrm{~nm}$ carbon-coated samples.

\subsection{EBSD}

Examination of a cross section was conducted with the same FE-SEM Zeiss $\Sigma$ igma HD system (Zeiss, Oberkochen, Germany) described above, equipped with an Oxford Instrument X-MaxN 80 SDD and a Nordlys EBSD detector (Oxford, Tubney Woods, Abingdon, Oxon, UK). Patterns were collected at variable pressure $(\mathrm{P}=50 \mathrm{~Pa})$, with high current and a $120 \mu \mathrm{m}$ aperture at $20 \mathrm{kV}$; the sample was tilted at $70^{\circ}$ for analysis. Prior to analysis, the cross section was ion milled under the following conditions: 15 min $2.5 \mathrm{kV}$ accelerating voltage, $1.5 \mathrm{kV}$ discharge voltage $\left(80^{\circ}\right)$; $15 \min 1 \mathrm{kV}$ accelerating voltage, $1.5 \mathrm{kV}$ discharge voltage $\left(80^{\circ}\right) ; 15 \mathrm{~min} 1 \mathrm{kV}$ accelerating voltage, $1.5 \mathrm{kV}$ discharge voltage $\left(70^{\circ}\right)$.

\section{9. $P y-G C / M S$}

Measurements were carried out on an Agilent 6890 gas chromatograph (Agilent Technologies, Santa Clara, CA, USA) equipped with a Frontier PY-2020iD Double-Shot vertical furnace pyrolyzer fitted with an AS-1020E Auto-Shot autosampler. The GC was coupled to a 5973N single quadrupole mass selective detector (MSD) (Agilent Technologies, Santa Clara, CA, USA). Samples of 30-50 $\mu \mathrm{g}$ were weighed out in deactivated pyrolysis sample cups (PY1-EC80F Disposable Eco-Cup LF) on a Mettler Toledo UMX2 Ultra microbalance. Samples were then either pyrolyzed without derivatization or derivatized with tetramethyl 
ammonium hydroxide (TMAH) before pyrolysis. Derivatization took place in the same cups as follows: $3-4 \mu \mathrm{L}$ of $25 \%$ TMAH in methanol (both from Fisher Scientific), depending on the sample size, were added directly to the sample in each cup with a $50 \mu \mathrm{L}$ syringe and, after $1 \mathrm{~min}$, loaded onto the autosampler. The interface to the GC was held at $320^{\circ} \mathrm{C}$ and purged with helium for $30 \mathrm{~s}$ before opening the valve to the GC column. The samples were then dropped into the furnace and pyrolyzed at $550{ }^{\circ} \mathrm{C}$ for $30 \mathrm{~s}$. The pyrolysis products were transferred directly to a DB-5MS capillary column $(30 \mathrm{~m} \times 0.25 \mathrm{~mm} \times 1 \mu \mathrm{m})$ with the helium carrier gas set to a constant flow of $1.5 \mathrm{~mL} / \mathrm{min}$. Injection with a $30: 1$ split was used, in accordance with the sample size. The GC oven temperature program was: $40{ }^{\circ} \mathrm{C}$ for $1 \mathrm{~min} ; 10^{\circ} \mathrm{C} / \mathrm{min}$ to $320^{\circ} \mathrm{C}$; isothermal for $1 \mathrm{~min}$. The Agilent 5973N MSD conditions were set as follows: transfer line at $320^{\circ} \mathrm{C}$, MS Quad $150{ }^{\circ} \mathrm{C}$, MS Source $230{ }^{\circ} \mathrm{C}$, electron multiplier at approximately $1770 \mathrm{~V}$; scan range 33-550 amu. For samples run with $\mathrm{TMAH}$, the detector was turned off until $3 \mathrm{~min}$ to avoid saturation by excess of the derivatizing agent and solvent. Data analysis was performed on an Agilent MSD ChemStation D.02.00.275 software by comparison with the NIST 2005 spectral libraries.

\subsection{Preparation of Cross Sections}

Samples were mounted in Technovit 2000 LC resin, cured under ultraviolet (UV) light for $20 \mathrm{~min}$, then polished using Micro-mesh cloths to expose the stratigraphy. Cross sections were examined by means of a Zeiss Axio Imager M2m microscope (Zeiss, Oberkochen, Germany), equipped with an Axiocam HRc digital camera (Zeiss, Oberkochen, Germany) and $50 \times, 100 \times, 200 \times, 400 \times$, and $500 \times$ magnifications. Photomicrographs were taken using the AxioVision 4.X.X software.

\section{Results and Discussion}

The main results of the analysis are summarized below, organized in sections that deal specifically with the canvas support and ground preparation, paint layers, and varnish. Table 1 presents an overview of the data collected from the micro-invasive investigation of the sample scrapings and cross sections removed from the painting.

Table 1. Summary of the compositions obtained with various micro-analytical techniques on sample scrapings and cross sections removed from Manet's Woman in Striped Dress. Sample S1 is not reported in the Table as it was too small to be mounted as a cross section.

\begin{tabular}{|c|c|c|c|c|}
\hline Samples & $\begin{array}{l}\text { Analytical } \\
\text { Techniques }\end{array}$ & Ground Preparation & $\begin{array}{l}\text { Pigments, Fillers, and Extenders } \\
\text { in Paint Layers }\end{array}$ & Varnish \\
\hline $\begin{array}{l}\text { (S2) Scraping of } \\
\text { uppermost varnish; } \\
\text { background, left of } \\
\text { center, top quadrant }\end{array}$ & $\begin{array}{c}\text { FTIR, } \\
\text { Py-GC/MS }\end{array}$ & - & - & $\begin{array}{l}\text { Diterpenoid natural } \\
\text { resin belonging to the } \\
\text { Pinaceae family, linseed } \\
\text { oil with possible } \\
\text { addition of driers }\end{array}$ \\
\hline $\begin{array}{l}\text { (S3) Cross section of } \\
\text { ground; proper right } \\
\text { edge, tape removed }\end{array}$ & $\begin{array}{l}\text { Optical } \\
\text { microscopy, } \\
\text { SEM/EDS }\end{array}$ & $\begin{array}{l}\text { Single-layer ground } \\
(20-50 \mu \mathrm{m}) \text { : coarse lead } \\
\text { white, with a few } \\
\text { particles of calcite, } \\
\text { barite, feldspar, and } \\
\text { carbon-based black }\end{array}$ & - & $\begin{array}{c}\text { One layer }(6-20 \mu \mathrm{m}), \\
\text { on top of ground } \\
\text { preparation }\end{array}$ \\
\hline $\begin{array}{l}\text { (S4) Cross section of } \\
\text { green paint; foliage, } \\
\text { proper right edge, } \\
\text { farther into painting }\end{array}$ & $\begin{array}{l}\text { Optical } \\
\text { microscopy, } \\
\text { SEM/EDS }\end{array}$ & $\begin{array}{l}\text { Single-layer ground } \\
(50 \mu \mathrm{m}) \text { : coarse lead } \\
\text { white, with a few } \\
\text { particles of calcite }\end{array}$ & $\begin{array}{c}\text { Top: Calcite, gypsum, Fe } \\
\text { oxide/oxy-hydroxide } \\
\text { Bottom: Emerald green, } \\
\text { ultramarine blue, cadmium yellow, } \\
\text { Naples yellow, vermilion, } \\
\text { Cr-based green (possibly viridian), } \\
\text { lead white, Fe } \\
\text { oxide/oxy-hydroxide, organic lake } \\
\text { on Al substrate }\end{array}$ & $\begin{array}{l}\text { Two layers (bottom } \\
10-20 \mu \mathrm{m} \text {, top } \\
5-10 \mu \mathrm{m} \text { ), on top of } \\
\text { paint layers }\end{array}$ \\
\hline
\end{tabular}


Table 1. Cont.

\begin{tabular}{|c|c|c|c|c|}
\hline Samples & $\begin{array}{l}\text { Analytical } \\
\text { Techniques }\end{array}$ & Ground Preparation & $\begin{array}{c}\text { Pigments, Fillers, and Extenders } \\
\text { in Paint Layers }\end{array}$ & Varnish \\
\hline $\begin{array}{l}\text { (S5) Scraping of green } \\
\text { paint; foliage, proper } \\
\text { right, top quadrant }\end{array}$ & $\begin{array}{l}\text { FTIR, } \\
\text { Raman }\end{array}$ & - & $\begin{array}{l}\text { Viridian, emerald green, lead } \\
\text { white (hydrocerussite) }\end{array}$ & $\begin{array}{l}\text { Natural resin and oil } \\
\text { (varnish and/or } \\
\text { binding medium) }\end{array}$ \\
\hline $\begin{array}{l}\text { (S6) Scraping of green } \\
\text { paint; foliage, right of } \\
\text { center, top quadrant }\end{array}$ & $\begin{array}{l}\text { FTIR, } \\
\text { Raman }\end{array}$ & - & $\begin{array}{c}\text { Viridian, ultramarine blue, chrome } \\
\text { yellow, lead white } \\
\text { (hydrocerussite), barite }\end{array}$ & $\begin{array}{l}\text { Natural resin and oil } \\
\text { (varnish and/or } \\
\text { binding medium) }\end{array}$ \\
\hline $\begin{array}{l}\text { (S7) Scraping of green } \\
\text { paint; foliage, left of } \\
\text { center, top quadrant }\end{array}$ & $\begin{array}{l}\text { FTIR, } \\
\text { Raman }\end{array}$ & - & $\begin{array}{l}\text { Viridian, ultramarine blue, } \\
\text { vermilion, red and yellow ochers, } \\
\text { chrome yellow, lead white } \\
\text { (cerussite), kaolinite }\end{array}$ & $\begin{array}{l}\text { Natural resin and oil } \\
\text { (varnish and/or } \\
\text { binding medium) }\end{array}$ \\
\hline $\begin{array}{l}\text { (S8) Scraping of green } \\
\text { paint; foliage, left of } \\
\text { center, top quadrant }\end{array}$ & $\begin{array}{l}\text { FTIR, } \\
\text { Raman }\end{array}$ & - & $\begin{array}{c}\text { Viridian, ultramarine blue, chrome } \\
\text { yellow, lead white } \\
\text { (hydrocerussite), barite }\end{array}$ & $\begin{array}{l}\text { Natural resin and oil } \\
\text { (varnish and/or } \\
\text { binding medium) }\end{array}$ \\
\hline $\begin{array}{l}\text { (S9) Cross section of } \\
\text { brown paint; foliage, } \\
\text { proper right edge, tape } \\
\text { removed }\end{array}$ & $\begin{array}{l}\text { Optical } \\
\text { microscopy, } \\
\text { SEM/EDS, } \\
\text { EBSD }\end{array}$ & $\begin{array}{l}\text { Single-layer ground } \\
(60-70 \mu \mathrm{m}) \text { : coarse lead } \\
\text { white, with a few } \\
\text { particles of calcite } \\
\text { and quartz }\end{array}$ & $\begin{array}{l}\text { Top: Lead white, cobalt blue, } \\
\text { ultramarine blue, emerald green, } \\
\text { malachite, cadmium yellow, Fe } \\
\text { oxide/oxy-hydroxide } \\
\text { Bottom: Lead white, cadmium } \\
\text { yellow, cobalt blue, ultramarine } \\
\text { blue, Cr-based green (possibly } \\
\text { viridian), emerald green, Fe } \\
\text { oxide/oxy-hydroxide, red lake on } \\
\text { Al substrate, Naples yellow, } \\
\text { malachite, quartz }\end{array}$ & $\begin{array}{l}\text { One layer }(3-6 \mu \mathrm{m}) \text {, on } \\
\text { top of paint layers }\end{array}$ \\
\hline $\begin{array}{l}\text { (S10) Cross section of } \\
\text { brown paint; foliage, } \\
\text { proper right edge, } \\
\text { farther into painting. } \\
\text { Broken into two } \\
\text { fragments, 10a and 10b }\end{array}$ & $\begin{array}{l}\text { Optical } \\
\text { microscopy, } \\
\text { SEM/EDS }\end{array}$ & $\begin{array}{l}\text { Single-layer ground } \\
(30 \mu \mathrm{m}) \text { : coarse lead } \\
\text { white, with a few } \\
\text { particles of calcite } \\
\text { and gypsum }\end{array}$ & $\begin{array}{c}\text { Top: Calcite, gypsum, Fe } \\
\text { oxide/oxy-hydroxide } \\
\text { Bottom: Lead white, cadmium } \\
\text { yellow, chrome yellow, cobalt blue, } \\
\text { ultramarine blue, Cr-based green } \\
\text { (possibly viridian), emerald green, } \\
\text { Fe oxide/oxy-hydroxide, red lake } \\
\text { on Al substrate, vermilion, Naples } \\
\text { yellow, Cu-based green (possibly } \\
\text { malachite), bone or ivory black, } \\
\text { cerulean blue, quartz }\end{array}$ & $\begin{array}{l}\text { Two layers (bottom } \\
6-25 \mu \mathrm{m} \text {, top } 3-6 \mu \mathrm{m} \text { ), } \\
\text { on top of paint layers }\end{array}$ \\
\hline $\begin{array}{l}\text { (S11) Scraping of green } \\
\text { paint; foliage, proper } \\
\text { right, top quadrant }\end{array}$ & $\begin{array}{l}\text { FTIR, } \\
\text { Raman }\end{array}$ & - & $\begin{array}{c}\text { Viridian, ultramarine blue, } \\
\text { vermilion, chrome yellow, lead } \\
\text { white (hydrocerussite), barite }\end{array}$ & $\begin{array}{l}\text { Natural resin and oil } \\
\text { (varnish and/or } \\
\text { binding medium) }\end{array}$ \\
\hline $\begin{array}{l}\text { (S12) Cross section of } \\
\text { pink-orange paint; } \\
\text { basket of flowers, near } \\
\text { proper right edge }\end{array}$ & $\begin{array}{l}\text { Optical } \\
\text { microscopy, } \\
\text { SEM/EDS }\end{array}$ & $\begin{array}{l}\text { Single-layer ground } \\
\text { (partial): coarse lead } \\
\text { white, with a few } \\
\text { particles of calcite }\end{array}$ & $\begin{array}{l}\text { Top: Lead white, barite, vermilion, } \\
\text { chrome yellow, red lakes on Al } \\
\text { and S substrates, emerald green, } \\
\text { gypsumBottom: Red ocher, lead } \\
\text { white, ultramarine blue, } \\
\text { cobalt blue }\end{array}$ & $\begin{array}{l}\text { Three layers: two in } \\
\text { between paint layers } \\
\text { (bottom } 2-5 \mu \mathrm{m} \text {, top } \\
4-5 \mu \mathrm{m}) \text {; one at top of } \\
\text { stratigraphy }(8-10 \mu \mathrm{m})\end{array}$ \\
\hline $\begin{array}{l}\text { (S13) Cross section of } \\
\text { green paint; foliage, } \\
\text { proper right, top } \\
\text { quadrant }\end{array}$ & $\begin{array}{l}\text { Optical } \\
\text { microscopy, } \\
\text { SEM/EDS }\end{array}$ & $\begin{array}{l}\text { Single-layer ground } \\
(10-40 \mu \mathrm{m}) \text { : coarse lead } \\
\text { white, with a few } \\
\text { particles of calcite, } \\
\text { barite, silicates, and } \\
\text { iron-containing earths }\end{array}$ & $\begin{array}{l}\text { Top: Cr-based green (possibly } \\
\text { viridian), ultramarine blue, } \\
\text { chrome yellow, lead white, barite, } \\
\text { Fe oxide/oxy-hydroxide, } \\
\text { vermilion, calcite } \\
\text { Bottom: Emerald green, lead } \\
\text { white, Fe oxide/oxy-hydroxide, } \\
\text { ultramarine blue, vermilion, } \\
\text { Naples yellow, zinc yellow, bone } \\
\text { or ivory black, calcite, barite }\end{array}$ & $\begin{array}{l}\text { Two layers: one in } \\
\text { between paint layers } \\
(5-15 \mu \mathrm{m}) \text {; one on top } \\
\text { of paint layers } \\
(20-40 \mu \mathrm{m})\end{array}$ \\
\hline
\end{tabular}


Table 1. Cont.

\begin{tabular}{|c|c|c|c|c|}
\hline Samples & $\begin{array}{l}\text { Analytical } \\
\text { Techniques }\end{array}$ & Ground Preparation & $\begin{array}{l}\text { Pigments, Fillers, and Extenders } \\
\text { in Paint Layers }\end{array}$ & Varnish \\
\hline $\begin{array}{l}\text { (S14) Cross section of } \\
\text { green paint; foliage, } \\
\text { proper left, top } \\
\text { quadrant }\end{array}$ & $\begin{array}{l}\text { Optical } \\
\text { microscopy, } \\
\text { SEM/EDS }\end{array}$ & - & $\begin{array}{l}\text { Cr-based green (possibly viridian), } \\
\text { chrome yellow, lead white, barite, } \\
\text { red ocher, calcite }\end{array}$ & None observed \\
\hline $\begin{array}{l}\text { (S15) Scraping of blue } \\
\text { paint; dress, near } \\
\text { proper left edge, } \\
\text { bottom quadrant }\end{array}$ & Raman & - & $\begin{array}{l}\text { Ultramarine blue, carbon-based } \\
\text { black }\end{array}$ & - \\
\hline $\begin{array}{l}\text { (S16) Scraping of blue } \\
\text { paint; dress, center of } \\
\text { picture }\end{array}$ & Raman & - & Ultramarine blue & - \\
\hline
\end{tabular}

\subsection{Canvas Support and Ground Preparation}

A comparison between the Lochard photograph and Woman in Striped Dress as seen in the Guggenheim's galleries (Figure 1) reveals that the picture underwent noticeable alterations before it arrived at the museum in 1965, as mentioned above. While retained by Manet's widow, Suzanne Manet, between 1883 and 1902, the painting was cut down on the left- and right-hand sides and trimmed at the top. The original size of the work was approximately $192 \times 124 \mathrm{~cm}$; by 1902 it measured about $180 \times 85 \mathrm{~cm}$; the current dimensions are $175.5 \times 84.3 \mathrm{~cm}$ [1]. While in the present case the change in canvas size appears to have been carried out after the artist's death, there are instances in which Manet himself would willfully extend his pictures by adding a piece of canvas to one side, divide a work into separate compositions and subsequently rejoin selected parts, or trim a painting from the top and bottom to adjust its shape [6]. Woman in Striped Dress is double lined with an aqueous adhesive and mounted onto a non-original, rather heavyweight stretcher, deliberately stained to a reddish-brown color. Traces of old tack holes along the edges, as well as microscopic cracking lines approximately $5 \mathrm{~mm}$ in from the existing cut edge, indicate that the canvas might have previously been folded around a slightly smaller stretcher than the one on which it is mounted today. At some point, tape was applied all around the edges of the picture-a practice that was often considered a neat way of completing a lining and is still in use today. Upon visual examination, the painting displays three small tears that may have prompted its lining, respectively located in the lower left of the floor area, in the skirt to the left of the model's proper left hand, and in the upper right corner.

Manet executed the painting on a canvas with a particularly fine weave considering its large size. Evidence of a preparatory drawing was not detected in the IR reflectogram, and the X-radiograph indicated that most of the composition was unchanged (Figure 3). Both suggest a remarkably direct and confident execution. The thin, off-white ground allows the texture of the canvas weave to remain prominent, a practice often favored by the Impressionists, with whom Manet was associated. SEM/EDS analysis of cross sections S3, S4, S9, S10, S10b, and S12 showed that the ground, varying in thickness between 20 and $70 \mu \mathrm{m}$, consists mainly of coarse lead white, with a few particles of calcite, gypsum, barite, quartz, feldspar, and a carbon-based black (Figure 4). 

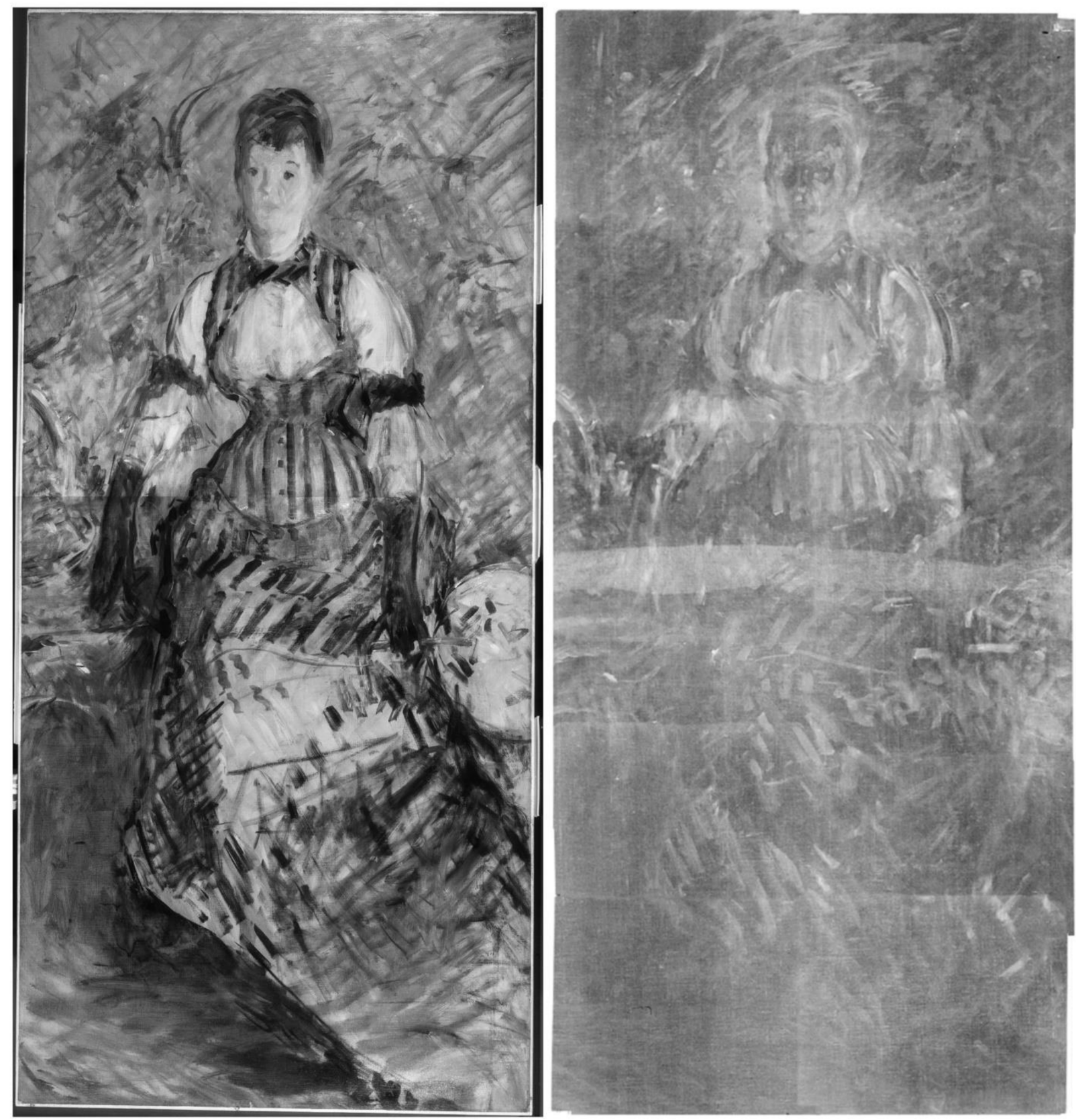

Figure 3. From left to right, IR reflectogram and X-radiograph of Manet's Woman in Striped Dress. 

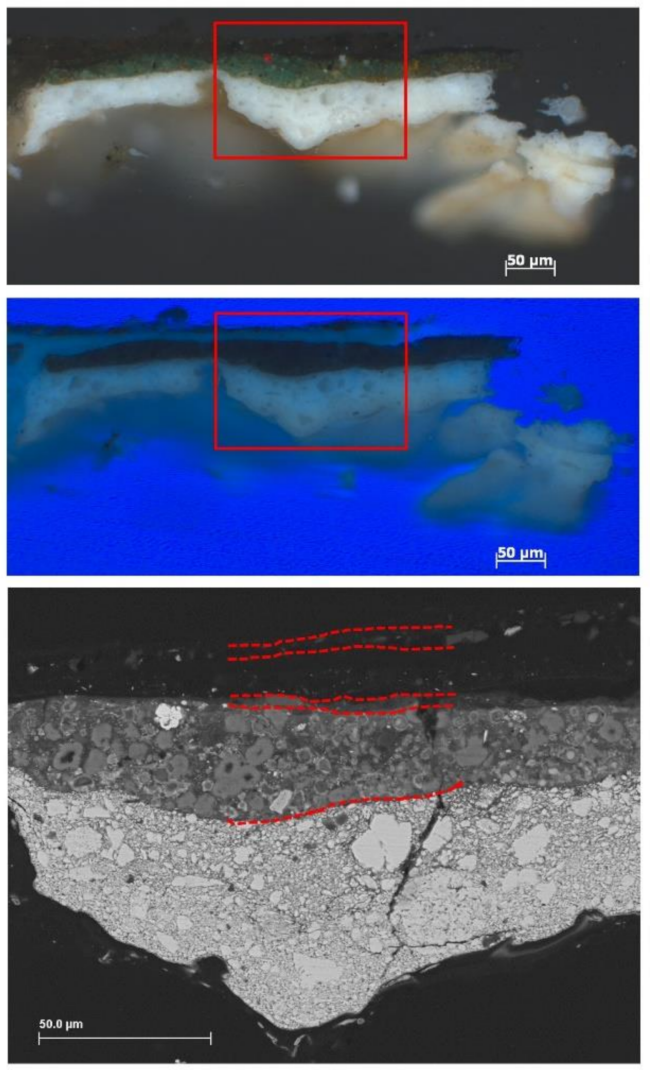
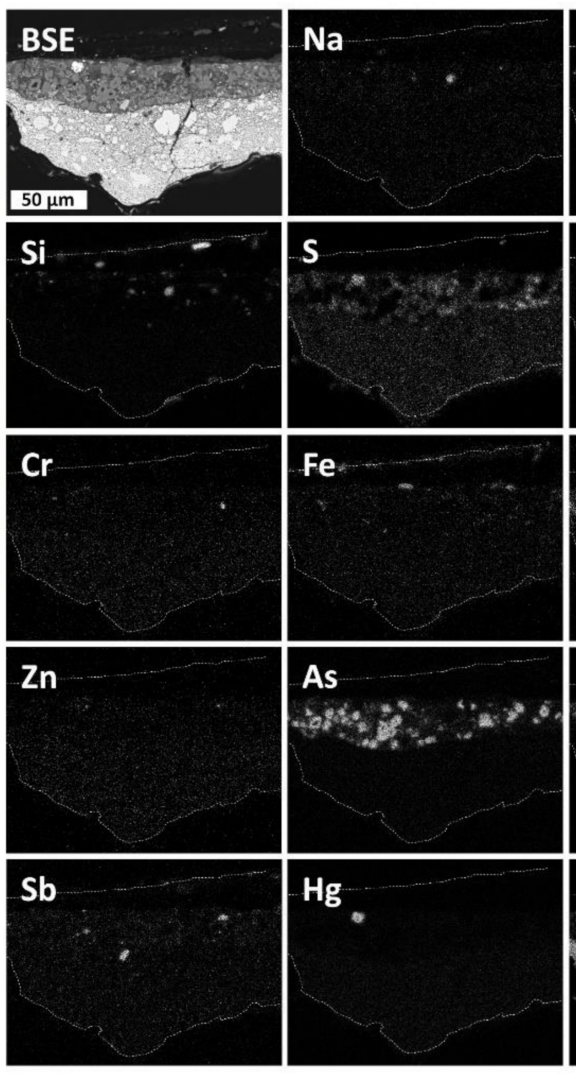
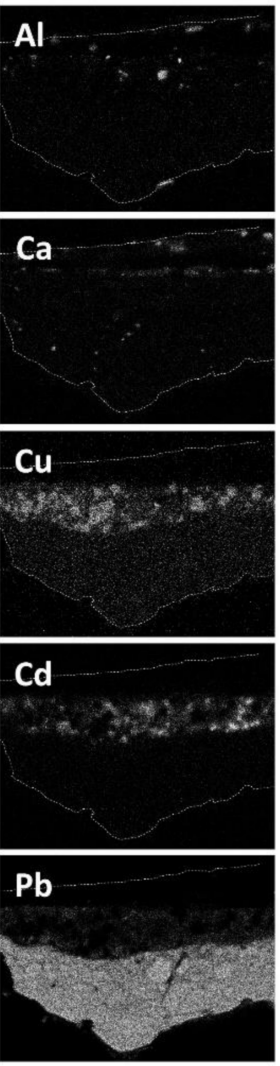

Figure 4. (Left) Photomicrographs of cross section S4 taken under polarized visible and UV light illuminations, respectively, and BSE image. S4 was removed from an area of foliage in the painting's proper right edge. In the photomicrographs, the red rectangles indicate the area where the BSE image and EDS elemental maps were acquired. (Right) EDS elemental maps of sodium (Na), aluminum ( $\mathrm{Al})$, silicon $(\mathrm{Si})$, sulfur (S), calcium (Ca), chromium (Cr), iron (Fe), copper (Cu), zinc ( $\mathrm{Zn})$, arsenic $(\mathrm{As})$, cadmium $(\mathrm{Cd})$, antimony $(\mathrm{Sb})$, mercury $(\mathrm{Hg})$, and lead $(\mathrm{Pb})$.

\subsection{Paint Layers}

As indicated above, a comparison of the portrait and Lochard photograph (Figure 1) betrayed painterly embellishments added by another hand or hands, especially over areas of exposed ground in the background, the model's right hand, and the decoration on the tabletop. In particular, while Manet originally only hinted at the background, the retouches added more detailed foliage, flowers, and a distinct rigid trellis-like pattern. These additions stood in striking contrast to Manet's deft brushwork and compressed the space around the main figure, resulting in a flattening effect. Moreover, the Louis XV side table, recurring in many of the artist's works, was originally located at a diagonal; the canvas reduction, which removed the table legs on the left, required that the table be seen almost straight on. As a result, the decorative element at the center of the table became one at its corner, and the suggestion of a leg was added, shifting the whole angle of the table within the composition. Besides altering the perspective, removal of the table legs from the left of the picture caused the woman, who was originally perched on or leaning against the table, to appear to be standing in a more precarious position. The graceful gesture of her proper right, gloved hand was also changed, resulting in a stiff, pointed extremity. Likewise, the lower right section of the model's skirt, which was only summarily sketched by Manet, was obscured at a later date with a thin, warm black paint, probably in an effort to cover the exposed ground and make this passage appear more finished. The model's proper right eyebrow, moreover, initially raised in a potentially mischievous fashion, was replaced with a thin mark that softened her visage and suppressed any alluring expression.

An inconspicuous calligraphic inscription that reads "Ed Manet" is evident on the table at center left. This inscription differs from the more usual robust signature found on 
other paintings by the artist, including Before the Mirror (1876), also at the Guggenheim (Suppl. Figure S1) [7]. When and by whom this inscription was applied is not known, although it appears to be directly on top of the original paint.

Thinner and washier in the background, the paint is characterized by some modest impasto in locations corresponding to the focus of the composition-the female figure and her fashionable garment, her fan, and the decorative carving on the table. Combined analysis of sample scrapings and cross sections by SEM/EDS, Raman, and FTIR spectroscopies showed that the various fields of color typically consist of numerous pigments, many of which are detected in trace amounts and may be unintentional, picked up from an unwashed brush or a much-used palette. The finding of complex mixtures, often including up to ten individual pigments within a single paint layer, is in keeping with previous studies of this artist's work by other research groups [4]. Materials identified in the ground and paint layers are consistent with those found in paintings by Manet in other collections $[4,6,8,9]$.

The foliage in the painting's background was identified as a critical area of possible posthumous reworking, which required in-depth analysis. Five microscopic scrapings (S5, S6, S7, S8, S11) were removed from different green shades in the top quadrant. Among these, sample S5 was found to be a mixture of viridian and emerald green; S6 and S8 contain viridian, ultramarine blue, and a lead chromate-based pigment (Figure 5); S7, of a distinctive olive green tone, is composed of the same three pigments, with the addition of vermilion, as well as red and yellow earths; S11 is based on viridian, ultramarine blue, a lead chromate-based pigment, and vermilion. All of these paint mixtures contain lead white, mostly present in the form of hydrocerussite; in addition, some include barite (S6, S8, S11) and kaolinite (S7) (Figure 5, right), probably as extenders. FTIR spectra of samples S6, S7, S8, and S11 also display a series of bands that are typical of metal carboxylates (Figure 5, right), most likely arising from the chemical interaction between the paint and oil medium.
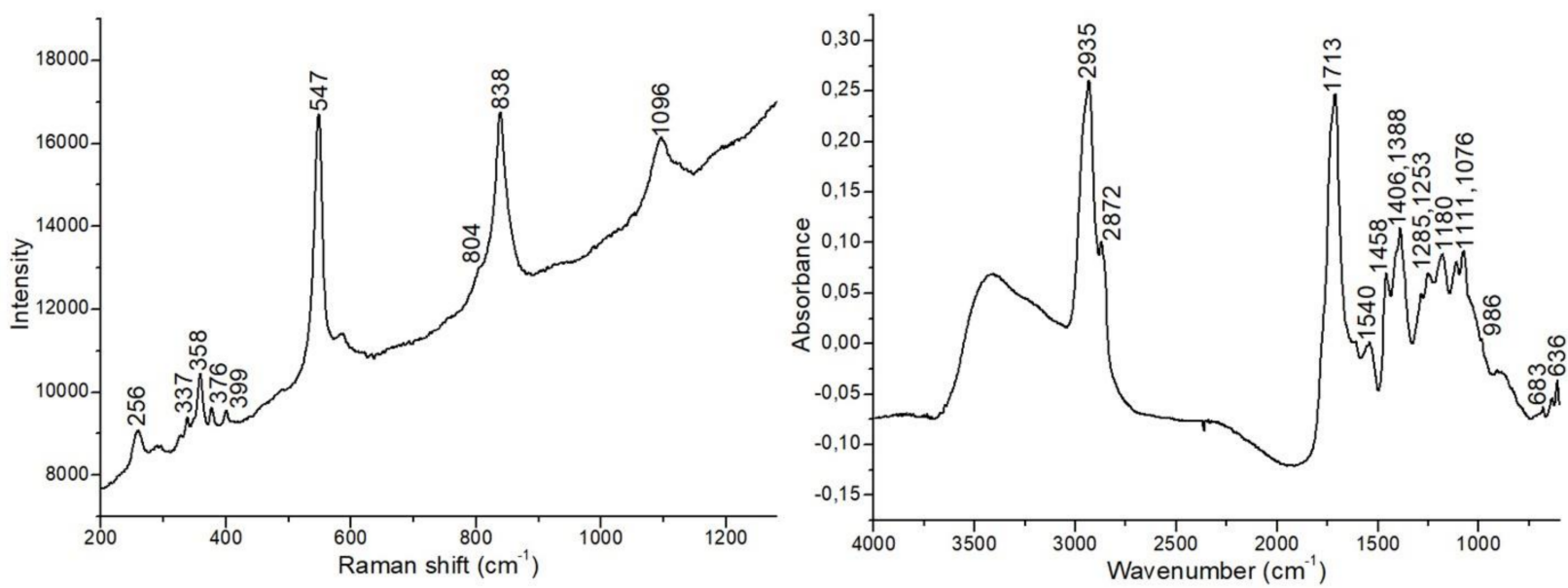

Figure 5. (Left) Raman spectrum of sample S6, i.e., a scraping of light green paint from an area of foliage in the painting's background at proper right, displaying the characteristic bands of ultramarine blue and a lead-chromate pigment. (Right) FTIR spectrum of the same sample, showing the distinctive signals of viridian, lead white in the form of hydrocerussite, barite, and metal carboxylates.

In addition to scrapings, seven cross sections (S4, S9, S10, S10b, S13, S14b, S14c) were taken from green and brown passages of foliage to study the paint stratigraphy. Microscopic observation of the cross sections under visible polarized light illumination revealed the structure of Manet's paint to be, mostly, a single layer applied directly over the ground, which the artist left visible in many passages. In sample S4, removed from an area of foliage in the painting's proper right edge, the green paint consists predominantly of emerald green, mixed with ultramarine blue, cadmium yellow, Naples yellow, a few particles of vermilion, a chromium-based green, possibly viridian, and traces of lead white, an iron-based compound, most likely an oxide or oxy-hydroxide, and aluminum-containing 
particles that are possibly the substrate of an organic lake (Figure 4). In cross section S9, taken from an area of the basket of flowers on the proper right edge where the tape had been removed, the green paint is a mixture of lead white, cadmium yellow, cobalt blue, ultramarine blue, a chromium-based green, possibly viridian, emerald green, an iron-based compound, a red lake precipitated onto an aluminum-based substrate, Naples yellow, a copper-based green, and a few quartz grains (Supplementary Figure S2). This copper-based green was confirmed as malachite by means of EBSD analysis, consistently with its particle morphology and chemical composition (Supplementary Figure S3). The same green layer detected in S9 is also present in S10 and S10b, collected from a location close to S9 yet farther into the painting. While the overall composition is the same, additional compounds were identified in these two specimens-namely, chrome yellow, vermilion, cerulean blue, and a bone or ivory black. In S9, the green layer was modified by the addition, most likely wet-on-wet, of a paint layer rich in fine particles of lead white, as well as a few particles of the same pigments found in the underlying layer; among them, cobalt blue, ultramarine blue, emerald green, malachite, cadmium yellow, and an iron-based compound, most likely an oxide or oxy-hydroxide. In S4, S10, and S10b, a discontinuous, relatively thin layer ( 3 to $10 \mu \mathrm{m}$ ) containing small, discrete particles of calcite and gypsum, as well as a few iron-containing particles, is present over the green paint.

Cross sections S4, S9, S10, and S10b, discussed above, are composed of a single layer of green paint, which is always located on top of the ground preparation and covered by a single or double varnish application (shown in Figure 4 for S4 and in Supplementary Figure S2 for S9). Conversely, sample S13, removed from an area of foliage in the painting's background near the proper right edge, appears to contain two distinct green paint layers: one applied directly over the ground; and a second one in the upper portion of the stratigraphy, sandwiched between two varnish applications (Figure 6). SEM/EDS analysis showed that the lowermost of these green paint layers is composed of a mixture of emerald green, lead white, iron oxide/oxy-hydroxides, ultramarine blue, as well as traces of vermilion, Naples yellow, zinc yellow, a bone or ivory black, calcite, and barite. The uppermost green layer contains a chromium-based green, possibly viridian, ultramarine blue, chrome yellow, and lead white, with abundant barite, as well as iron oxide/oxy-hydroxides, a few minuscule vermilion and calcite particles (Figure 6). The top paint layer was also observed and analyzed in cross sections S14b and S14c, taken from an area of green foliage at the opposite side of the painting, near its proper left edge. A combined elemental map showing the distributions of chromium, mainly concentrated in the upper paint layers as a chrome yellow and a chromium-based green, possibly viridian, and of copper, due to the emerald green present in the bottom paint layers, is presented in Figure 7.

While paint layers applied directly over the ground are presumed to be original, those found on top of a varnish, as in the case of S13, likely point to later additions. All pigments detected in the sample scrapings and cross sections of green paint were known and available at the end of the 19th century [10], indicating that, albeit posthumous with respect to the original composition, the uppermost paint in S13 could have been applied shortly after the artist's death.

Comparison with the Lochard photograph showed that the basket of flowers, too, was likely reworked after Manet's death. As such, this site was deemed of particular interest and deserving investigation. Photomicrographs taken under visible and UV illuminations of cross section S12, removed from one of the pink-orange petals, revealed a complex stratigraphy, including, above the ground, a yellow-brown layer, followed by two varnish applications, a pink-orange layer, and one additional varnish application (Supplementary Figure S5). As mentioned above, the observed location of the yellow-brown paint, applied directly over the ground, points to the possibility of this being original paint; conversely, the fact that the pink-orange paint is lying on top of two varnish layers indicates a possible later addition. The yellow-brown paint is composed of an iron-based compound and silicates, most likely present as a red ocher, along with lead white, ultramarine blue, and a few cobalt blue particles. The pink-orange paint contains lead white, barite, vermilion, 
chrome yellow, two red lakes-one with aluminum and sulfur and, possibly, one with a tin-based substrate, and a few emerald green and gypsum particles (Supplementary Figure S5). As observed in the samples of green paint, all pigments detected in S12 were available at the time in which the work was created [10]; thus, these later embellishments could have been introduced soon after Manet's death.
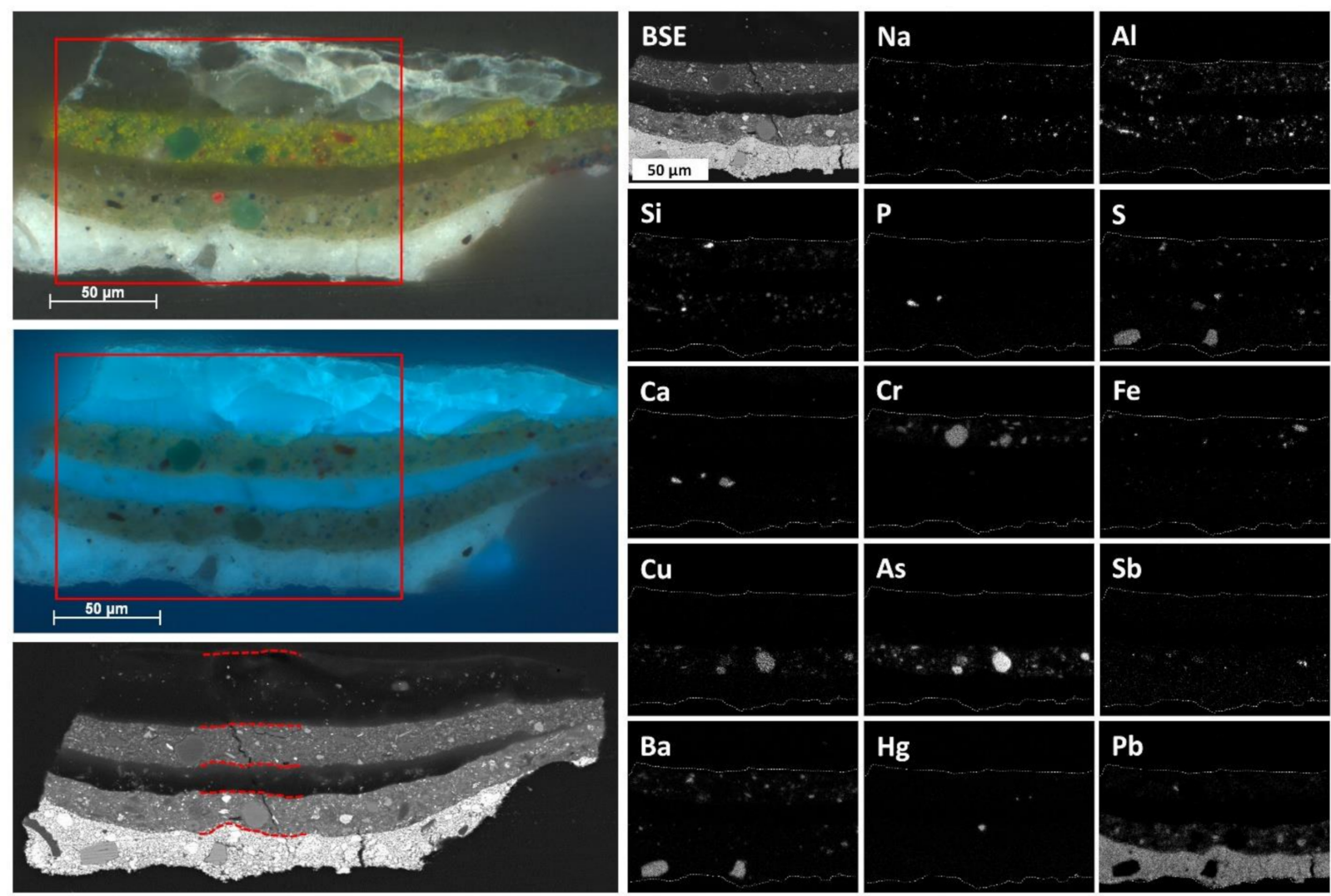

Figure 6. (Left) Photomicrographs of cross section S13 taken under polarized visible and UV light illuminations, respectively, and BSE image. S13 was removed from an area of foliage in the painting's background near the proper right edge. In the photomicrographs, the red rectangles indicate the area where the BSE image and EDS elemental maps were acquired. (Right) EDS elemental maps of sodium (Na), aluminum (Al), silicon (Si), phosphorus (P), sulfur (S), calcium (Ca), chromium $(\mathrm{Cr})$, iron $(\mathrm{Fe})$, copper $(\mathrm{Cu})$, arsenic $(\mathrm{As})$, antimony $(\mathrm{Sb})$, barium $(\mathrm{Ba})$, mercury $(\mathrm{Hg})$, and lead $(\mathrm{Pb})$.

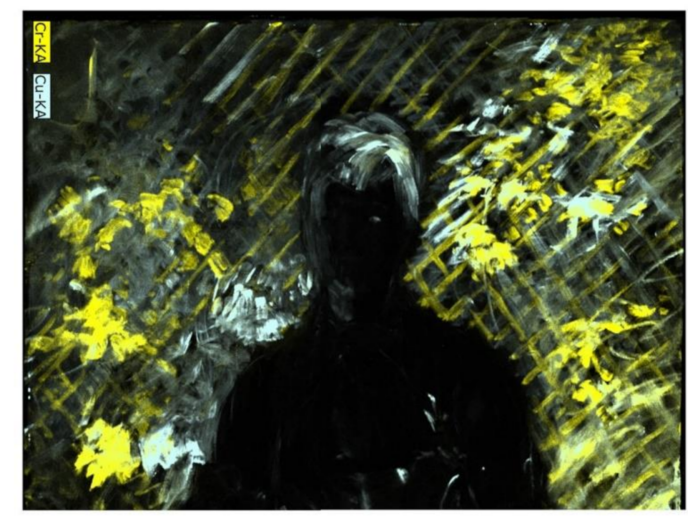

Figure 7. Combined elemental distribution maps acquired by MA-XRF in the topmost quadrant of the painting: copper $(\mathrm{Cu}$, light blue) and chromium $(\mathrm{Cr}$, yellow). The area where these maps were acquired is indicated by a red rectangle in Supplementary Figure S4, in the Supplementary Information file. 
MA-XRF elemental maps revealed that the grayish-white and black-looking stripes of the dress were painted with lead white and a calcium-containing black pigment (Figure 8, left). Moreover, chromium and copper are also present in these areas, suggesting a more complex pigment mixture. Raman analysis of two samples removed from distinct areas of the dress, S15 and S16, showed that its dark coloration is mainly due to ultramarine blue, and that Manet combined this pigment with a bone black or ivory black for the darker blue strokes outlining the skirt in the lower right. The woman's face was created with just a few assured brushstrokes over a thin, earth-colored, dry scumble of vermilion and iron-containing earths (Figure 8, right). The MA-XRF map shown in Figure 8 at right also revealed that her eyes were painted primarily using cobalt blue, with a hint of brown paint-again, likely an iron-containing earth-in her proper left eye and that her lips were made with vermilion, although traces of several other pigments were added to subtly adjust the color shades.
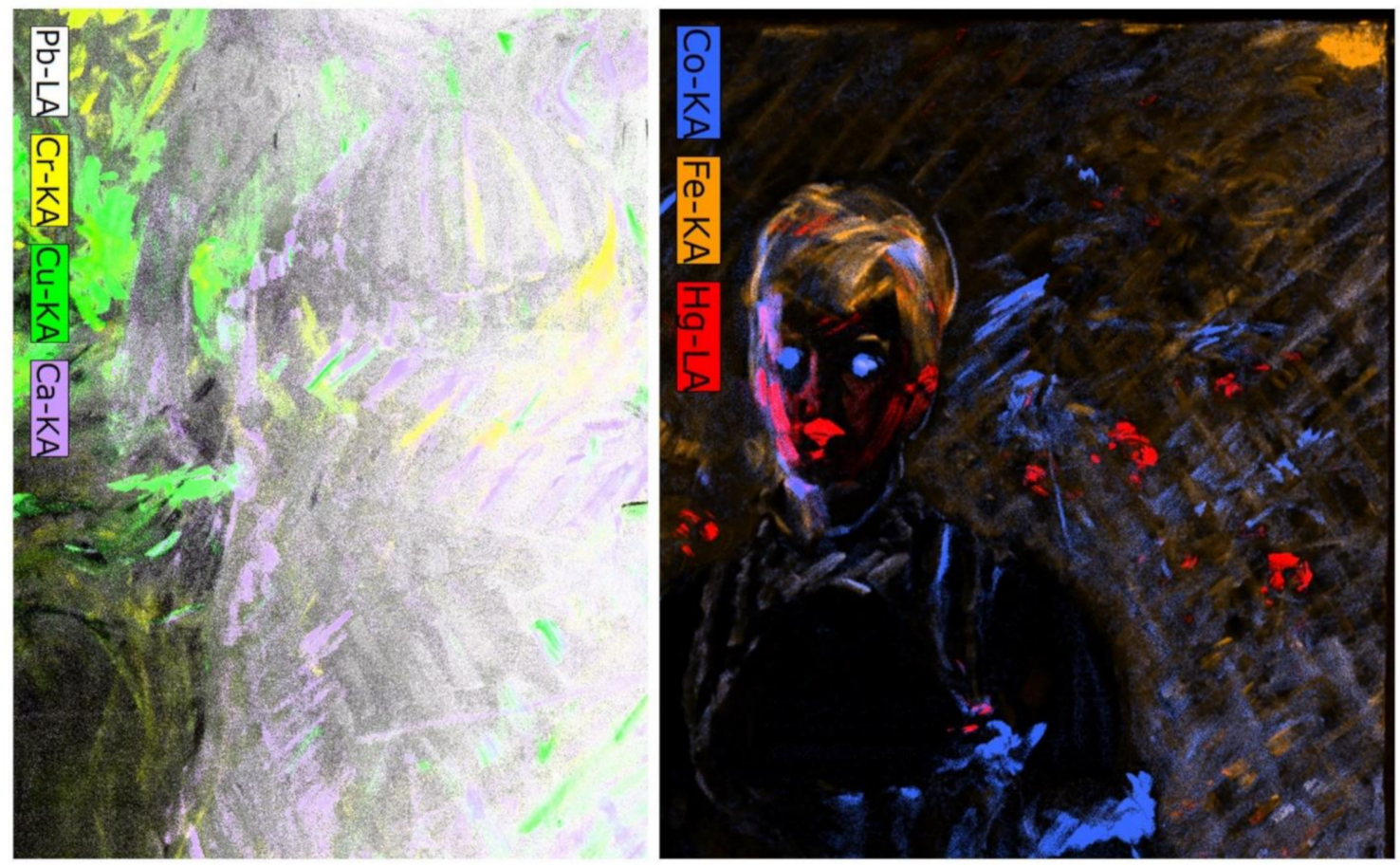

Figure 8. Combined elemental distribution maps acquired by MA-XRF in two areas of the painting. (Left) Area of the sitter's dress: lead $(\mathrm{Pb}$, white), chromium $(\mathrm{Cr}$, yellow), copper $(\mathrm{Cu}$, green), and calcium (Ca, violet); (Right) Area in the upper right quadrant: cobalt ( $\mathrm{Co}$, blue), iron (Fe, orange), and mercury $(\mathrm{Hg}$, red). The areas where these maps were acquired are indicated by green and blue rectangles in Supplementary Figure S4, in the Supplementary Information file.

\subsection{Varnish}

Examination with optical microscopy and SEM/EDS analysis of sample cross sections provided useful information on the number of varnish layers present in various areas of the picture and their locations within the stratigraphy. Sample S3, for instance, was taken from a site on the painting's proper right edge where the tape had been removed. Photomicrographs of this cross section display a 6 to $20 \mu \mathrm{m}$ thick varnish on top of the ground preparation (Supplementary Figure S6), which is thought to be an initial coating applied before any of the embellishments were added to the composition and tape was applied around the work's edges. Sample S4, collected from a location on the proper right edge, close to S3, although farther into the painting, shows two varnish layers, the uppermost of which has an average thickness of 5-10 $\mu \mathrm{m}$ and was likely applied after the tape and within its borders. Similar observations to those made for samples S3 and S4 apply to S9 and S10, taken from a lower portion of the painting's proper right edge-the first from a site where the tape had been removed, the latter (broken into two fragments, $\mathrm{S} 10$ and S10b) farther into the composition. In these cases, too, the samples display one 
and two varnish layers, respectively, the uppermost one appearing generally thinner than the lowermost application. Flakes of a copper and zinc alloy detected in samples S10 and $\mathrm{S} 10 \mathrm{~b}$ are interpreted as residues from the brass gilding of the painting's historic frame.

Transmission FTIR analysis of a scraping of the most superficial varnish removed from an area in the painting's background at top (S2) detected mostly a natural resin (Figure 9, left). Py-GC/MS analysis provided a more detailed characterization of the sample components, showing the presence of several oxidation products of abietic acid, including methyl abietate, methyl 6-dehydrodehydroabietate, 7-methoxytetrahydroabietic acid, 15methoxydehydroabietic acid, 7-oxodehydroabietic acid, 7,15-dimethoxytetradehydroabietic acid, and 15-methoxydehydroabietic acid (Figure 9, right). These compounds are indicative of a diterpenoid natural resin belonging to the Pinaceae family [11]. In addition, glycerol along with azelaic, palmitic, and stearic acids were identified, suggesting the presence of an oil [12]. While fatty acid ratios cannot always be relied upon to provide a detailed characterization of the oil, in this case, the relative ratio of palmitic acid to stearic acid $(\mathrm{P} / \mathrm{S}=1.65)$ suggests the presence of linseed oil, while the slightly elevated relative ratio of azelaic acid to palmitic acid $(\mathrm{A} / \mathrm{P}=1.9)$ may indicate the addition of driers. More frequently employed for wood furniture or musical instruments rather than modern paintings, a varnish of such composition has been often described as an inexpensive alternative to more traditional artists' varnishes [13].
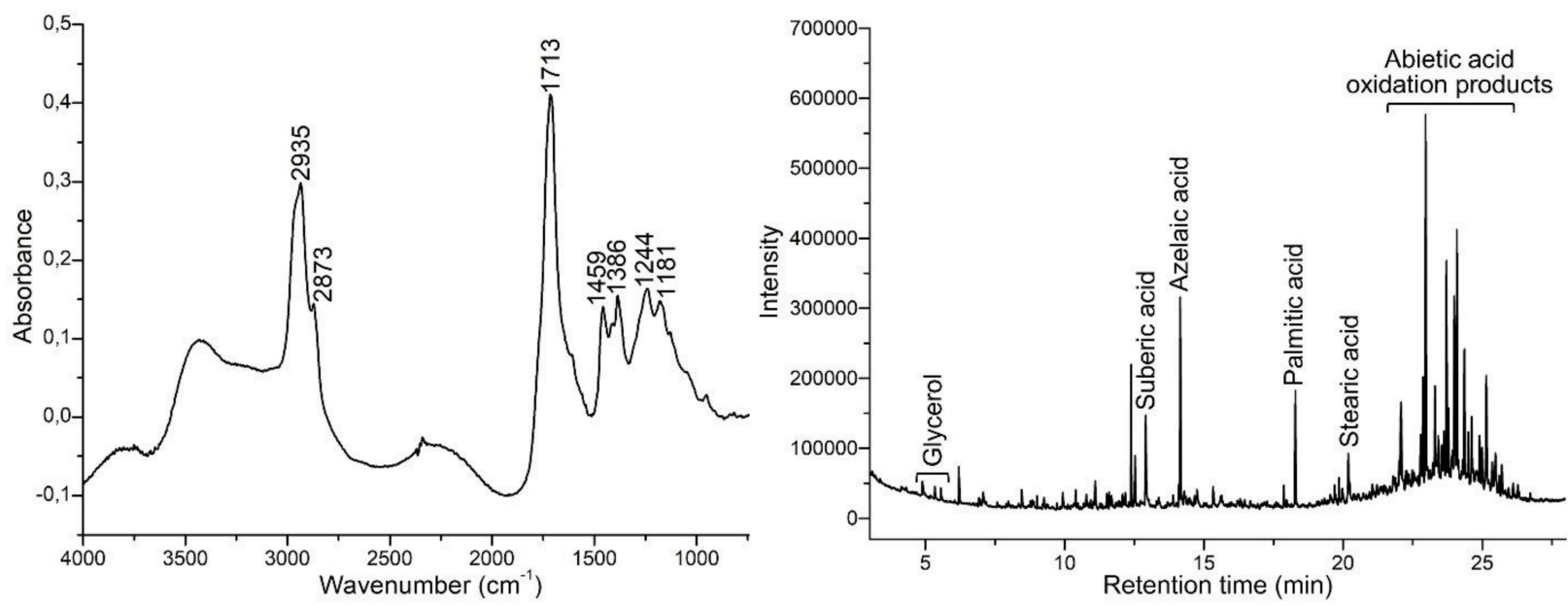

Figure 9. (Left) FTIR spectrum of sample S2, i.e., a scraping of the uppermost varnish from an area in the painting's background at top, displaying the characteristic bands of a natural resin. (Right) Py-GC/MS chromatogram of sample S2 obtained with TMAH derivatization. Materials identified include Pinaceae resin and oil. Marker compounds were detected as methylated derivatives.

\section{Conclusions}

This article describes the salient results of a technical study on Woman in Striped Dress, a large-scale portrait by Édouard Manet in the Thannhauser collection of the Solomon R. Guggenheim Museum, New York. The goal of this research, a collaboration between the Guggenheim's Conservation and Curatorial Departments and The Met's DSR, was to illuminate the original materials and posthumous alterations of this masterpiece in support of an ongoing conservation treatment. Scientific analysis, along with comparative examination of today's picture with a photograph taken by Fernand Lochard after Manet's death, uncovered substantial changes that had been made to the painting before it was promised as a gift to the Guggenheim in 1963, first arriving at the institution as an extended loan in 1965. Among these are subsequent reductions in size, several retouches and embellishments likely motivated by a desire to make the work appear more "finished", thus marketable, as well as at least three varnishing campaigns. Overall, these revisions had severely compromised the appearance of Manet's picture. 
The examination of cross section samples removed from locations possibly affected by later retouches revealed the presence of at least one intermediate varnish layer, confirming the posthumous nature of the superficial paint application. However, all materials in the ground and paint layers are consistent with those found in paintings by the same artist in other collections and were in use in the second half of the 19th century, which indicates that these later embellishments may have been introduced shortly after Manet's death. Analysis of a sample scraping of the uppermost varnish layer detected a natural diterpenoid resin of the Pinaceae family mixed with linseed oil—a more common formulation for wooden objects rather than modern paintings. In addition to analysis and observation with UV light and stereomicroscopy, the solubility parameters of the varnishes, retouching, and original paint layers were quite distinct and aided in the identification of dissimilar materials. This combined information was crucial to devise and guide a conservation treatment for the painting, which took place between 2015 and 2018 in an attempt to remove the discolored varnish and select areas of retouching. This treatment approach privileged the artist's hand, while retaining and integrating some historical-albeit later-elements in a holistic way to preserve the painting's overall aesthetic (Figure 10).
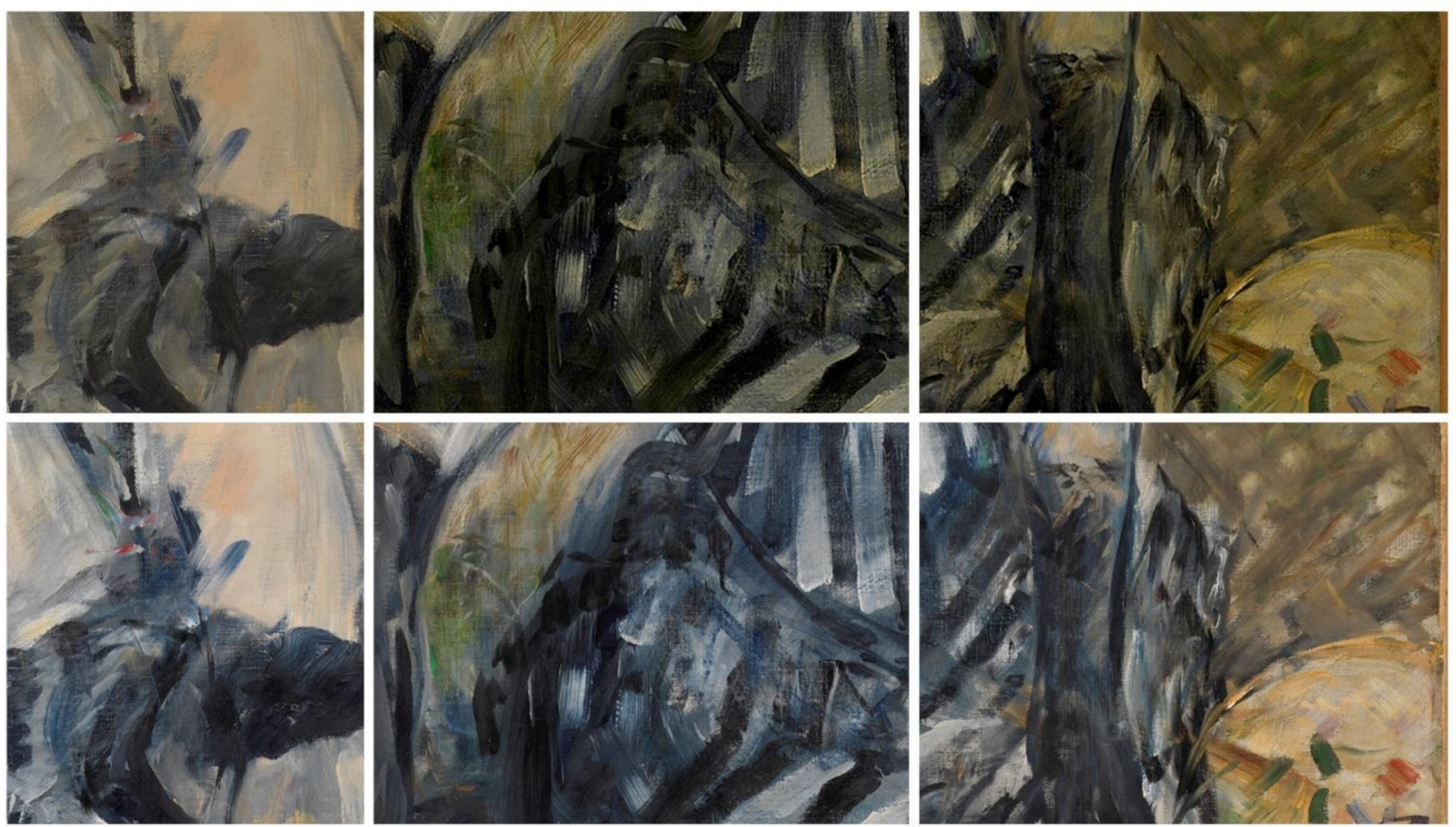

Figure 10. Three areas of the painting, from left to right details of the corsage, dress and glove, shown before (top) and after (bottom) cleaning. (C) Solomon R. Guggenheim Foundation, New York.

Upon varnish removal, some of the paint strokes in areas of later retouching appeared dense and flat, in contrast with Manet's inspired technique, always characterized by bright and broad brushwork, even in the presence of complex pigment mixtures. After cleaning, the object on the table, historically cast as a basket of flowers, was reinterpreted as, possibly, a bouquet or a hat with silk flowers. Notably, the woman's dress, which had for decades read as black and off-white, was, after treatment, revealed to be of a nuanced palette of grayish-white and black with a deep blue-violet hue. These colors concur with Théodore Duret's description in his 1902 monograph on Manet, which characterized the dress as striped "grises-violettes" [14]. While the painting may never be restored to its original scale and state, the scientific work and conservation treatment described in this article contributed to the return of Woman in Striped Dress to a closer approximation of its original appearance. 
Supplementary Materials: The following are available online at https://www.mdpi.com/article/10 .3390/coatings11111334/s1, Figure S1: Inscription found on Woman in Striped Dress (left) compared to Manet's signature on Before the Mirror (right), Figure S2: Optical microscopy and SEM/EDS data acquired on cross Section S9, Figure S3: EBSD data acquired on cross Section S9, Figure S4: Areas of the painting where the MA-XRF elemental distribution maps shown in Figures 7 and 8 were acquired, Figure S5: Optical microscopy and SEM/EDS data acquired on cross Section S12, Figure S6: Optical microscopy and SEM/EDS data acquired on cross Section S3.

Author Contributions: F.P. coordinated the study, removed samples, prepared cross sections, carried out optical microscopy, point XRF, FTIR, Raman, Py-GC/MS, as well as part of SEM/EDS analysis and data interpretation, and wrote the initial draft of this manuscript with inputs from all other authors. S.A.C. acquired, processed, and interpreted the MA-XRF data. F.C. conducted part of the SEM/EDS and EBSD analysis and data interpretation. S.A.C. and F.C. contributed to the overall interpretation of the micro-analytical results obtained on the paint samples. G.M. V.G., and L.S. provided art historical context, treatment information, data from IR reflectography, X-radiography, microscopic examination of the painting, and supported the scientific work. This article includes excerpts from a conservation entry and an art historical essay by G.M., V.G. and F.P., and significantly expands the materials information gleaned from scientific analysis. All authors have read and agreed to the published version of the manuscript.

Funding: This research was made possible by the Network Initiative for Conservation Science (NICS), a Metropolitan Museum of Art program. Support for NICS was provided by a grant (31500630) from The Andrew W. Mellon Foundation. Conservation on this painting was made possible by a grant to the Solomon R. Guggenheim Museum from the Bank of America Conservation Project.

Institutional Review Board Statement: Not applicable.

Informed Consent Statement: Not applicable.

Data Availability Statement: All data generated during this study are either included in this published article or available from the corresponding author upon reasonable request.

Acknowledgments: The authors are indebted to Charlotte Hale and Michael Gallagher in The Met's Department of Paintings Conservation for generously supporting this project. The authors are also grateful to Brunella Santarelli and Louisa Smieska, former fellows in The Met's DSR, for assisting with the EBSD and MA-XRF analysis, respectively. In addition, FP would like to acknowledge Anna Cesaratto for her initial contribution to this project during her time at The Met working in the NICS program. The Guggenheim authors wish to thank, most especially, Juliet Wilson-Bareau, Anne Distel, and Charles F. Stuckey. Among our current and former Guggenheim colleagues, we are indebted to Julie Barten, Tracey Bashkoff, Susan Davidson, and Megan Fontanella. We owe special gratitude to David and Zahira Bomford, Aviva Burnstock, and Maureen Cross. We also thank Scott Allen, Carol Armstrong, Elsa Badie Modiri, Vivian Endicott Barnett, Barbara Buckley, Helen Burnham, Nick Brandreth, Jacklyn Chi, S. Hollis Clayson, Nicholas Eastaugh, Thierry Ford, Isabel Gaëtan, Gloria Groom, Sven Haase, Jean-Gabriel Lopez, Paul Messier, Dianne Dwyer Modestini, Doug Munson, Debra Hess Norris, Mark Osterman, Isolde Pludermacher, Aileen Ribeiro, Marie Robert, Betsy Rosasco, Valerie Steele, Susan Alyson Stein, MaryAnne Stevens, Françoise Tétart- Vittu, Jennifer Thompson, John Vincler, Christina Zuccari, and Frank Zuccari.

Conflicts of Interest: The authors declare no conflict of interest.

\section{References}

1. McMillan, G.; Pozzi, F. Édouard Manet, Woman in Striped Dress, Materials and Process. In Thannhauser Collection: French Modernism at the Guggenheim; Fontanella, M., Ed.; Guggenheim Museum Publications: New York, NY, USA, 2018; pp. 108110, 298.

2. Greene, V.; McMillan, G. Revealing Édouard Manet's Woman in Striped Dress. In Thannhauser Collection: French Modernism at the Guggenheim; Fontanella, M., Ed.; Guggenheim Museum Publications: New York, NY, USA, 2018; pp. 111-115, $298-300$.

3. Proust, A. Édouard Manet (Souvenirs). La Rev. Blanche 1897, 12, 132-133.

4. Hanson, A.C. Manet and the Modern Tradition; Yale University Press: New Haven, CT, USA, 1977; p. 160.

5. Stuckey, C.F. Manet Revised: Whodunit? Art Am. 1983, 71, 158-177, 239-241.

6. Bomford, D.; Roy, A. Manet's "The Waitress": An Investigation into its Origin and Development. Natl. Gallery Tech. Bull. 1983, 7, 3-19. 
7. McMillan, G. Édouard Manet, Before the Mirror, Materials and Process. In Thannhauser Collection: French Modernism at the Guggenheim; Fontanella, M., Ed.; Guggenheim Museum Publications: New York, NY, USA, 2018; pp. 104-106.

8. Groom, G.; Westerby, G. (Eds.) Manet Paintings and Works on Paper at the Art Institute of Chicago. 2017. Available online: https://publications.artic.edu/manet/reader/manetart/ (accessed on 5 August 2021).

9. Amato, S.R.; Burnstock, A.; Cross, M.; Janssens, K.; Rosi, F.; Cartechini, L.; Fontana, R.; Fovo, A.D.; Paolantoni, M.; Grazia, C.; et al. Interpreting Technical Evidence from Spectral Imaging of Paintings by Édouard Manet in the Courtauld Gallery. X-Ray Spectrom. 2019, 48, 282-292. [CrossRef]

10. Eastaugh, N.; Walsh, V.; Chaplin, T.; Siddall, R. Pigment Compendium. A Dictionary and Optical Microscopy of Historic Pigments; Butterworth-Heinemann: Oxford, UK, 2004.

11. van den Berg, K.J.; Boon, J.J.; Pastorova, I.; Spetter, L.F. Mass Spectrometric Methodology for the Analysis of Highly Oxidized Diterpenoid Acids in Old Master Paintings. J. Mass Spectrom. 2000, 35, 512-533. [CrossRef]

12. Mills, J.; White, R. Organic Chemistry of Museum Objects, 2nd ed.; Butterworth-Heinemann: Oxford, UK, 1994.

13. White, R.; Kirby, J. A Survey of Nineteenth- and Early Twentieth-Century Varnish Compositions Found on a Selection of Paintings in the National Gallery Collection. Natl. Gallery Tech. Bull. 2001, 22, 64-84.

14. Duret, T. Histoire d'Édouard Manet et de Son Oeuvre; H. Floury: Paris, France, 1902. 